\title{
Pituitary hyperplasia causing complete bitemporal hemianopia with resolution following surgical decompression: case report
}

\author{
Nataly Raviv, MD, ${ }^{1}$ Ami Amin, MD, ${ }^{2}$ Tyler J. Kenning, MD, ${ }^{1}$ Carlos D. Pinheiro-Neto, MD, PhD, ${ }^{3}$ \\ David Jones, MD, ${ }^{4}$ Vibhavasu Sharma, MD, ${ }^{2}$ and Maria Peris-Celda, MD, PhD ${ }^{1}$
}

Departments of ${ }^{1}$ Neurosurgery, ${ }^{2}$ Endocrinology, and ${ }^{4}$ Pathology, Albany Medical College; and ${ }^{3}$ Department of Surgery, Division of ENT, Albany Medical College, Albany, New York

\begin{abstract}
In this report, the authors demonstrated that idiopathic pituitary hyperplasia $(\mathrm{PH})$ can cause complete bitemporal hemianopia and amenorrhea, even in the setting of mild anatomical compression of the optic chiasm and normal pituitary function. Furthermore, complete resolution of symptoms can be achieved with surgical decompression.

$\mathrm{PH}$ can occur in the setting of pregnancy or end-organ insufficiency, as well as with medications such as oral contraceptives and antipsychotics, or it can be idiopathic. It is often found incidentally, and surgical intervention is usually unnecessary, as the disorder rarely progresses and can be managed by treating the underlying etiology. Here, the authors present the case of a 24 -year-old woman with no significant prior medical history, who presented with bitemporal hemianopia and amenorrhea. Imaging revealed an enlarged pituitary gland that was contacting, but not compressing, the optic chiasm, and pituitary hormone tests were all within normal limits. The patient underwent surgical decompression of the sella turcica and exploration of the gland through an endoscopic endonasal transsphenoidal approach. Pathology results demonstrated $\mathrm{PH}$. A postoperative visual field examination revealed complete resolution of the bitemporal hemianopia, and menstruation resumed 3 days later. The patient remains asymptomatic with no hormonal deficits.
\end{abstract}

https://thejns.org/doi/abs/10.3171/2020.5.JNS20448

KEYWORDS pituitary hyperplasia; bitemporal hemianopia; endoscopic endonasal transsphenoidal approach; pituitary surgery

$\mathrm{P}$ ITUITARY hyperplasia $(\mathrm{PH})$ is defined as the proliferation of one or more adenohypophyseal cell types., ${ }^{1,2}$ It can occur in the setting of pregnancy or end-organ insufficiency with disruption of normal feedback circuits, as well as with medications such as oral contraceptives and antipsychotics, or it can be idiopathic. ${ }^{1}$ It is often found incidentally, and surgical intervention is usually unnecessary, as the disorder rarely progresses and can be managed by treating the underlying etiology. ${ }^{3}$ Here, we report a case of idiopathic PH in a patient who developed complete bitemporal hemianopia and amenorrhea despite benign imaging and laboratory findings.

\section{Case Report}

History and Examination

A 24-year-old woman with no significant prior medi- cal history presented with a 3-week experience of visual disturbances. She was evaluated by a neuroophthalmologist who identified a left inferotemporal visual field defect. Brain MRI 4 weeks after symptom onset revealed a 4- to 5-mm hypoenhancing focus within the inferior aspect of the anterior pituitary gland that was concerning for either a pituitary microadenoma or a small pars intermedia cyst. The gland appeared enlarged with a height of $11 \mathrm{~mm}$, and although it was seen to be touching and minimally abutting the chiasm, no significant anatomical compression was identified (Fig. 1). The patient had also experienced amenorrhea over the previous 7 months with a negative pregnancy test, as well as an increase in mood swings, hair loss, and stuttering. However, pituitary function tests were within normal limits (Table 1). The patient was not taking any medications, and there was no clear etiology for her symptoms. Given the minimal mass effect on the 

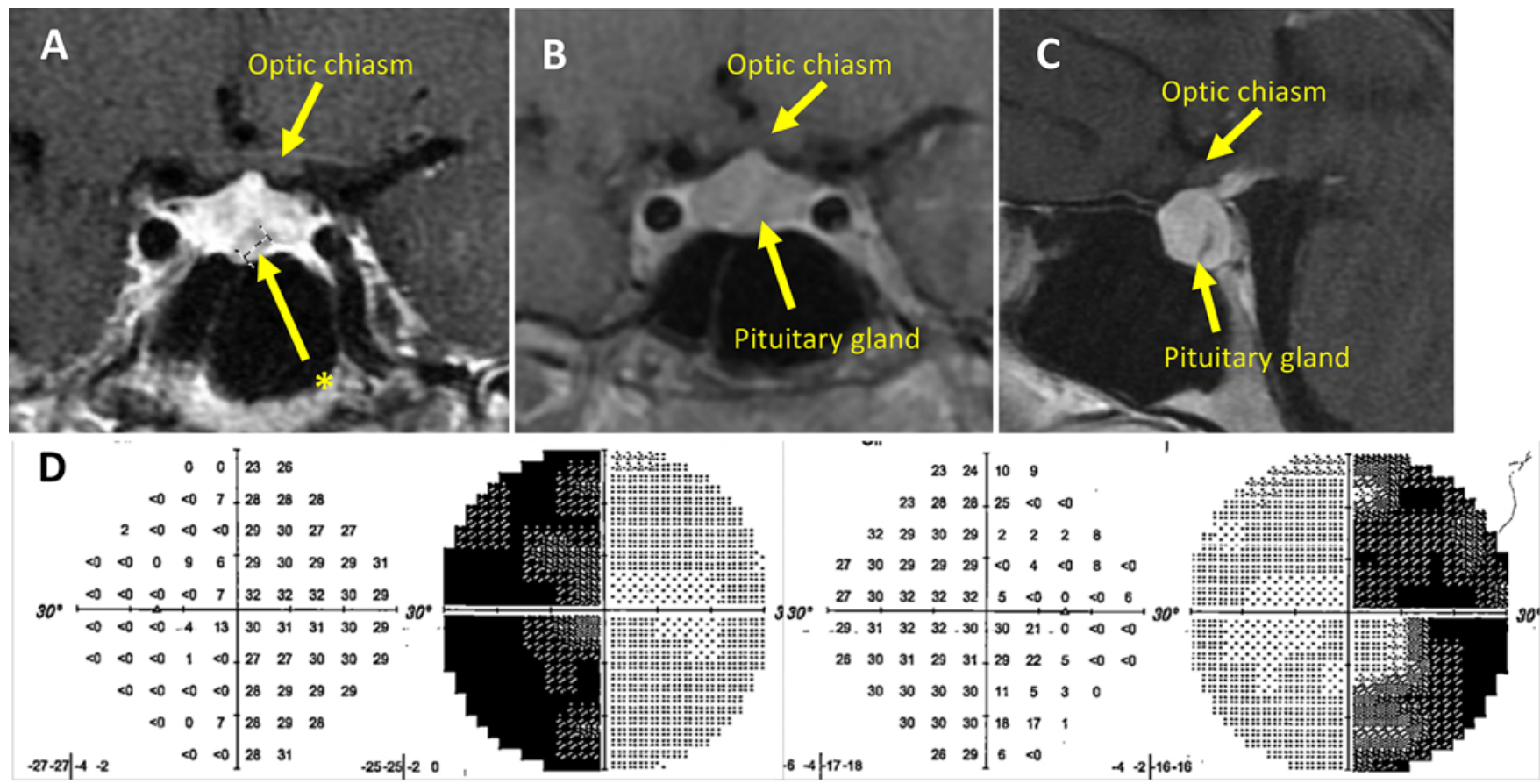

FIG. 1. Initial coronal T1-weighted gadolinium-enhanced MR image (A) showing a hypointense lesion, possibly a microadenoma or small pars intermedia cyst (asterisk), in an enlarged pituitary gland in contact with the optic chiasm. Preoperative coronal (B) and sagittal (C) MR images obtained 4 weeks later. The previously shown hypointensity is not clearly visualized, and the anatomical relationship of the pituitary gland with the optic chiasm has not changed. Note that the patient has a small pars intermedia cyst, best seen on sagittal images, which was also present on the initial image and unchanged 4 weeks later. Pituitary gland dimensions: $11 \mathrm{~mm}$ craniocaudal, $17 \mathrm{~mm}$ transverse, $9 \mathrm{~mm}$ anteroposterior. Visual fields (D) showing bitemporal hemianopia at the time of the second MRI session. Figure is available in color online only.

gland and normal pituitary function, we chose to continue observing the patient, and no surgical intervention was offered.

Her visual symptoms worsened over the next 2 weeks, and follow-up visual field testing at that time demonstrated

TABLE 1. Preoperative pituitary function test results

\begin{tabular}{lcc}
\hline \multicolumn{1}{c}{ Hormone } & Level & $\begin{array}{c}\text { Reference Ranges for 24-Yr-Old } \\
\text { Woman }\end{array}$ \\
\hline ACTH $(\mathrm{pg} / \mathrm{ml})$ & 17 & $0-46$ \\
\hline Cortisol $(\mu \mathrm{g} / \mathrm{dl})$ & 6.7 & $3.1-16.7$ \\
\hline TSH $(\mu \mathrm{lU} / \mathrm{ml})$ & 1.71 & $0.45-4.50$ \\
\hline Free T4 $(\mathrm{ng} / \mathrm{dl})$ & 0.92 & $0.6-1.3$ \\
\hline IGF-1 $(\mathrm{ng} / \mathrm{ml})$ & 241 & $87-368$, mean 237 \\
\hline GH $(\mathrm{ng} / \mathrm{ml})$ & 0.080 & $\leq 6$ \\
\hline Testosterone $(\mathrm{ng} / \mathrm{dl})$ & 77 & $10-75$ \\
\hline Prolactin $(\mathrm{ng} / \mathrm{ml})$ & 11.0 & $3.3-26.7$ \\
\hline LH $(\mathrm{mlU} / \mathrm{ml})$ & 11.8 & $\begin{array}{c}\text { Follicular: } 2.1-10.9 \\
\text { Midcycle: } 19.1-103.0 \\
\text { Luteal: } 1.2-12.9\end{array}$ \\
\hline FSH $(\mathrm{mlU} / \mathrm{ml})$ & & Follicular: $3.8-8.8$ \\
& 4.5 & Midcycle: $4.4-22.5$ \\
& & Luteal: $1.8-5.1$ \\
\hline
\end{tabular}

$\mathrm{ACTH}=$ adrenocorticotropic hormone; $\mathrm{FSH}$ = follicle-stimulating hormone; $\mathrm{GH}$ = growth hormone (somatotropin); IGF-1 = insulin-like growth factor 1 ; LH = luteinizing hormone; $\mathrm{T} 4$ = thyroxine; $\mathrm{TSH}$ = thyroid-stimulating hormone. progression of the visual field defect to complete bitemporal hemianopia. Repeat MRI 8 weeks after the first visual symptoms started (4 weeks after the initial MRI) showed no significant changes, with exception of the disappearance of the 4- to 5-mm hypoenhancing focus. Given the progression of her symptoms without alternative causes, the patient was offered sellar decompression, biopsy, and gland exploration, and she elected to proceed with surgical intervention.

\section{Operation}

One week after the last MRI study was performed, the patient underwent an endoscopic endonasal transsphenoidal approach with drilling and removal of the anterior and inferior walls of the sella turcica, dural opening, biopsy, and exploration of the gland. The dura mater was widely opened, and the gland partially herniated through the sellar opening into the sphenoid sinus (Fig. 2A-D). The pituitary gland was exposed, and ring curettes were utilized to explore and dissect the surface of the gland laterally along both sides toward the cavernous sinuses and superiorly toward the diaphragm. Two small vertical incisions were made in the gland, and special attention was directed to the area at which a possible microadenoma had been located on the initial MRI. Only a biopsy of the gland was performed with no further tissue resection, as no tumor was identified. The gland was dissected from the diaphragm of the sella inferiorly, and this maneuver provided space and allowed the gland to protrude toward the sphenoid sinus. 
Raviv et al.
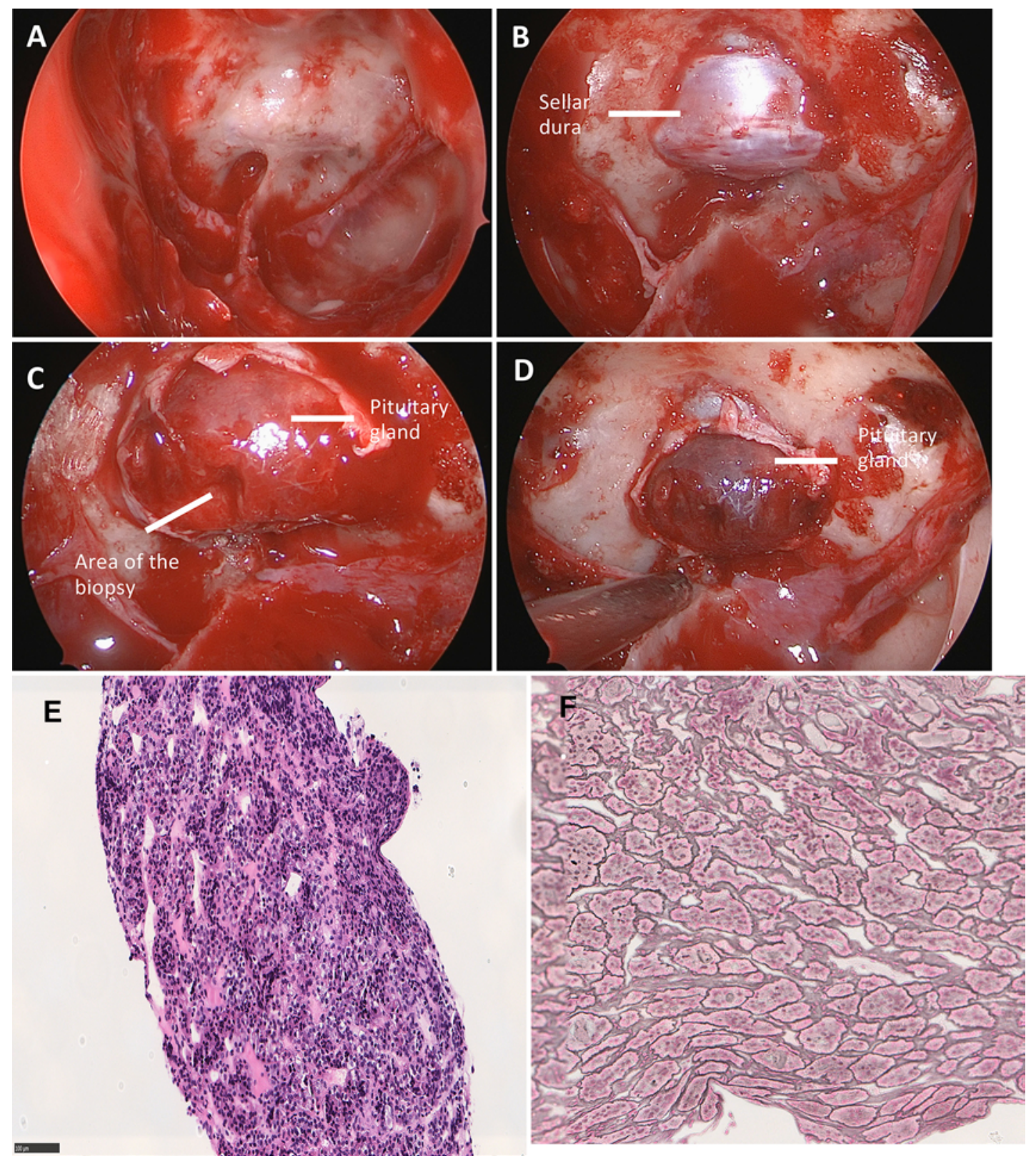

FIG. 2. Intraoperative images. A: Sphenoid sinus. B: Dural exposure of the sella after bony decompression. C: The dura mater of the sella was widely opened, two small vertical incisions were made in the gland, and special attention was directed to the area at which a possible microadenoma had been located on the initial MR image (just superior to the sphenoid septation in the inferior aspect of the sella). A biopsy of the gland was performed, and no tumor was identified. D: Final image after hemostasis before reconstruction with a free mucosal graft. Note the herniation of the pituitary gland toward the sphenoid sinus. E: Adenohypophysis with expanded acini composed of uniform bland pituicytes consistent with $\mathrm{PH}$. H \& E, original magnification $\times 100$. F: Adenohypophysis with centrally located expanded acini and conventional anterior pituitary tissue along the periphery. Reticulin, original magnification $\times 200$. Figure is available in color online only.

Frozen pathology was suggestive of hyperplasia (Fig. $2 \mathrm{E}$ and F). Permanent pathology demonstrated minimal expansion of the acinar growth pattern, without evidence of adenoma formation, vasculitis, inflammation, or neoplasia. Staining revealed diffuse S100 positivity without CD68 or Ki-67 expression. Both PAS and PAS/diastase stains were negative, and the reticulin stain revealed a largely intact acinar network with minimal expansion of the acini. These findings are consistent with PH. Immunohistochemistry for anterior pituitary hormones was not performed, as no tumor was identified and the patient's laboratory results were normal.

\section{Postoperative Course}

The patient's vision improved immediately after surgery, and a 2-week follow-up visual field examination re- 

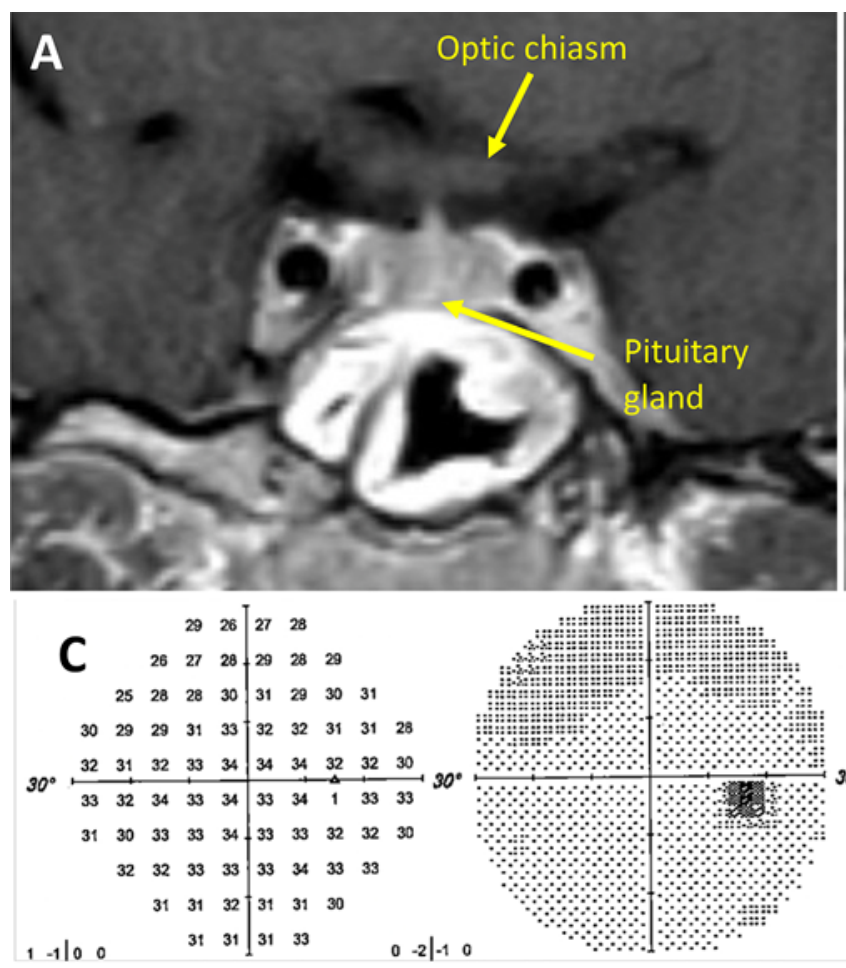

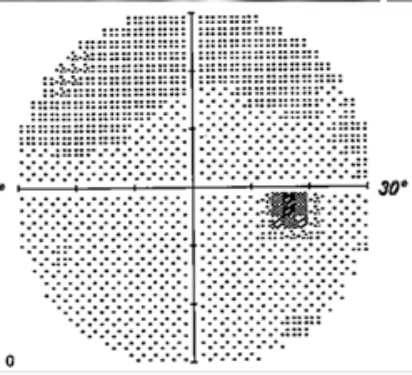

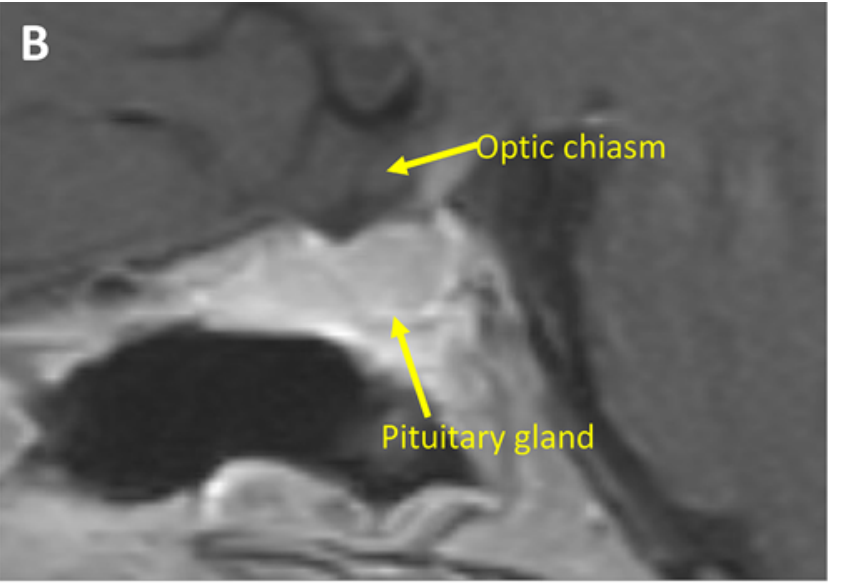

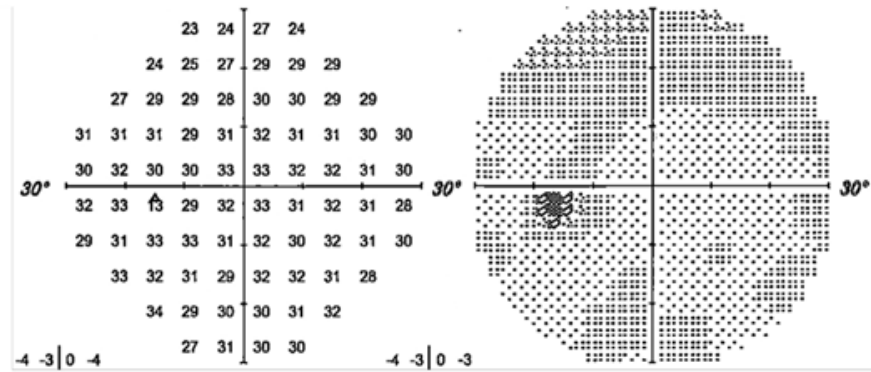

FIG. 3. Three-month postoperative coronal (A) and sagittal (B) gadolinium-enhanced T1-weighted MR image showing an increased distance between the pituitary gland and the optic chiasm as compared to that on the preoperative MR image. Visual field results $(\mathbf{C}) 2$ weeks after surgery showing complete recovery. Figure is available in color online only.

vealed complete resolution of the bitemporal hemianopia (Fig. 3). Menstruation resumed 3 days postoperatively, and pituitary function, including cortisol levels, was within normal limits postoperatively. The optic chiasm was shown to be decompressed on follow-up imaging. The patient remains asymptomatic.

\section{Discussion}

Pituitary size may vary according to patient sex and age. In a neuroradiological series, pituitary height on average was found to be higher in women than in men (mean 5.35 vs $4.93 \mathrm{~mm}$, respectively) and peaked in the 20- to 29 -year age group. Normal pituitary height is considered to be $<9 \mathrm{~mm}$ in patients $20-29$ years of age and $<8 \mathrm{~mm}$ otherwise. ${ }^{1,4}$ Gland enlargement in a young, healthy woman may be defined as a height $\geq 9 \mathrm{~mm}$, and this may be found in less than $0.5 \%$ of women aged $18-35$ years. ${ }^{3,4}$

PH resulting in enlargement of the pituitary gland may be attributable to either a physiological or pathological process. ${ }^{5}$ Pathological etiologies include such diagnoses as primary hypothyroidism or gonadal insufficiency, and physiological PH can occur in youth, pregnancy, or menopause. ${ }^{1}$ Authors examining pituitary enlargement in a series of 7 female patients 15-27 years of age concluded that an incidentally discovered enlarged pituitary gland $>$ $9 \mathrm{~mm}$ should be considered normal physiological pituitary hypertrophy when the MRI and hormonal tests are otherwise unremarkable, and they suggested that imaging and endocrine follow-up may not be necessary. ${ }^{3}$ According to these definitions, the present case can be defined as physi- ological $\mathrm{PH}$; however, our patient became progressively symptomatic and experienced bitemporal hemianopia and amenorrhea despite benign imaging and laboratory findings.

Visual field defects are a known symptom of pituitary macroadenomas given compression of the optic chiasm. Bitemporal hemianopia is the classic finding of these lesions, although most patients who have visual symptoms experience other patterns of deficit, such as variable bitemporal, monocular, homonymous, or mixed defects. ${ }^{6}$ Ho et al. ${ }^{7}$ evaluated the relationship between pituitary size and visual impairment and demonstrated that pituitary adenomas $<2 \mathrm{~cm}$ in size generally have no or minimal effect on vision. ${ }^{7}$

Lee et al. ${ }^{6}$ examined 119 patients with pituitary macroadenomas who underwent imaging and formal visual field assessments. MRI studies were evaluated for optic pathway displacement, and findings were classified as no contact, abutment but no displacement, mild displacement $(<3 \mathrm{~mm})$, and moderate displacement $(\geq 3 \mathrm{~mm})$. Notably, only 1 patient had true bitemporal hemianopia. In 23 patients the tumors were found to have no contact with the optic pathway, whereas in 8 patients the tumors were abutting but not displacing the optic pathway. Upon visual field assessment of these patients with no or minimal contact with the optic chiasm, 17 of 23 and 3 of 8 patients, respectively, were found to have visual field deficits. ${ }^{6}$ The etiology of the visual field deficits without clear compression was attributed to regression of a previously compressive tumor, hormonal influences, autonecrosis, or vascular shunting. ${ }^{6,8}$ 
Two case reports in the literature have described $\mathrm{PH}-$ related visual field defects in adolescents, one case causing transient visual defects associated with exercise and spontaneously resolving and the other attributable to pituitary apoplexy in a hyperplastic gland. The latter case was treated with surgical decompression. ${ }^{3,9}$ Another case report has described transient physiological pituitary enlargement and visual loss in a pregnant woman that resolved in the postpartum period. ${ }^{10}$ In our case report, the patient's symptoms were continuous and worsened during the observation period, but she was not in a physiological transient state such as pregnancy. We, therefore, elected to offer surgical intervention.

To our knowledge, the present report constitutes the only case with a severe progressive visual deficit related to histologically documented $\mathrm{PH}$ with no associated hemorrhage and resolution following surgical decompression. With regard to this case, the fact that surgical decompression of the pituitary gland achieved complete and immediate resolution of the symptoms likely implicates anatomical compression rather than an alternative etiology as the cause of the profound deficit. With no hormonal alterations and no tumor identified on the updated MRI, we believed that further incisions and a more thorough exploration of the gland would not be of benefit. Surgical decompression with attention to performing an ample opening of the sellar bone with exposure of the dura mater anteriorly and inferiorly, as well as dissection from the diaphragm, was important to provide space for the gland to expand inferiorly.

It is possible that PH may have a lower threshold than macroadenomas in terms of the degree of anatomical compression of the optic chiasm required to cause visual deficits. This may be attributable to the engorgement and firmness of the gland in PH as compared with macroadenomas, which are less vascular and softer. However, most patients with $\mathrm{PH}$ remain asymptomatic, and it is unknown why some patients exhibit symptoms while others do not. Regarding patients who do have symptoms, we demonstrated that surgical decompression of the pituitary gland can be considered in cases of an enlarged pituitary gland consistent with $\mathrm{PH}$ and visual field deficits, regardless of the degree of compression.

\section{References}

1. De Sousa SM, Earls P, McCormack AI. Pituitary hyperplasia: case series and literature review of an under-recognised and heterogeneous condition. Endocrinol Diabetes Metab Case Rep. 2015;2015:150017.
2. Melmed S. Mechanisms for pituitary tumorigenesis: the plastic pituitary. J Clin Invest. 2003;112(11):1603-1618.

3. Chanson P, Daujat F, Young J, et al. Normal pituitary hypertrophy as a frequent cause of pituitary incidentaloma: a follow-up study. J Clin Endocrinol Metab. 2001;86(7): 3009-3015.

4. Tsunoda A, Okuda O, Sato K. MR height of the pituitary gland as a function of age and sex: especially physiological hypertrophy in adolescence and in climacterium. AJNR Am J Neuroradiol. 1997;18(3):551-554.

5. Jameson JL, De Groot LJ. Endocrinology: Adult and Pediatric E-Book. Elsevier Health Sciences; 2015.

6. Lee IH, Miller NR, Zan E, et al. Visual defects in patients with pituitary adenomas: the myth of bitemporal hemianopsia. AJR Am J Roentgenol. 2015;205(5):W512-W518.

7. Ho RW, Huang HM, Ho JT. The influence of pituitary adenoma size on vision and visual outcomes after trans-sphenoidal adenectomy: a report of 78 cases. J Korean Neurosurg Soc. 2015;57(1):23-31.

8. Levy A. Pituitary disease: presentation, diagnosis, and management. J Neurol Neurosurg Psychiatry. 2004;75(suppl 3): iii47-iii52.

9. Kinoshita Y, Yamasaki F, Tominaga A, et al. Physiologic pituitary hyperplasia causing visual disturbance during adolescence. J Clin Neurosci. 2019;61:279-281.

10. Inoue T, Hotta A, Awai M, Tanihara H. Loss of vision due to a physiologic pituitary enlargement during normal pregnancy. Graefes Arch Clin Exp Ophthalmol. 2007;245(7): 1049-1051.

\section{Disclosures}

Dr. Kenning reports being a consultant for Stryker CMF and Collagen Matrix.

\section{Author Contributions}

Conception and design: Peris-Celda, Raviv. Acquisition of data: Peris-Celda, Raviv, Kenning, Pinheiro-Neto, Jones. Analysis and interpretation of data: Peris-Celda, Raviv, Jones. Drafting the article: Raviv. Critically revising the article: Peris-Celda, Raviv. Reviewed submitted version of manuscript: all authors. Study supervision: Peris-Celda, Pinheiro-Neto.

\section{Supplemental Information}

\section{Previous Presentations}

This case was presented as a poster presentation at the North American Skull Base Society Annual Meeting held in San Antonio, Texas, on February 7-9, 2020.

\section{Correspondence}

Maria Peris-Celda: Albany Medical College, Albany, NY. periscm@amc.edu. 